Revista Iberoamericana, Vol. LXVII, Núm. 197, Octubre-Diciembre 2001, 687-707

\title{
¿ADÓNDE VA LA LITERATURA? \\ LA ESCRITURA, LA LECTURA Y LA CRÍTICA ENTRE LA GALAXIA GÜTEMBERG Y LA GALAXIA ELECTRÓNICA
}

\author{
POR \\ Gisela Kozak Rovero \\ Universidad Central de Venezuela
}

Para los que hemos sido formados en el estudio de la literatura y nos hicimos adultos y profesionales en la galaxia electrónica ${ }^{1}$ y en pleno debate sobre las características, consecuencias y fracasos de la modernidad, el ejercicio de la crítica parte siempre de la conciencia de que nuestro objeto de estudio debe proyectarse en toda su historicidad. Es decir, hacer crítica literaria hoy requiere tener en cuenta la discusión sobre la noción de lo literario en tanto discurso específico, las implicaciones ideológicas de la valoración estética y del concepto de canon, la confrontación de la cultura letrada frente a otras configuraciones simbólicas, el cuestionamiento a la idea de humanismo, la caída de las utopías político-sociales en el continente y los nuevos caminos abiertos por los Estudios Culturales, los Estudios de Género, etcétera. Es decir, estudiar literatura significa implícitamente reflexionar sobre las discusiones académicas actuales. Pero, además, es preciso reflexionar igualmente sobre los “modos de leer” (Martín Barbero) propiciados por los medios de comunicación de masas y la informática, la situación del libro en tanto formato en tensión con los generados por las computadoras, las condiciones particulares de producción, difusión y recepción de la literatura en relación con la influencia de la electrónica, el mercado editorial actual y la profunda segmentación del público.

Este trabajo parte de una concepción eminentemente "cultural” del problema de la creación, recepción y difusión literarias en nuestras sociedades, en el sentido de entender la cultura como las condiciones del saber, del sentir, del percibir y del socializar que predominan en un momento histórico dado (Martín Barbero, “Nuevos modos de leer” 19). Por ende, los “modos de leer” y las posibles transformaciones de eso que llamamos convencionalmente "literatura", son irreductibles a los formatos tecnológicos (Chartier 38), pues están imbricadas concepciones del mundo que moldean la manera particular en

\footnotetext{
${ }^{1}$ Este trabajo tiene una deuda con mi colega y amigo Vicente Lecuna, compañero del Departamento de Teoría de la Literatura de la Escuela de Letras de la Universidad Central de Venezuela. Nuestras posiciones respecto a la literatura son radicalmente distintas pero secretamente complementarias. Parte del título de este artículo, "la galaxia electrónica”, es una variación del título del libro de Lecuna: La ciudad letrada en el planeta electrónico. La situación actual del intelectual latinoamericano. Madrid: Pliegos, 1999, libro imprescindible para abordar muchas de las problemáticas actuales del ejercicio intelectual.
} 
que la entrada de las tecnologías modifica las condiciones propias del campo literario. ${ }^{2}$ Por eso es tan importante entender que la literatura ha perdido parte de su protagonismo en una época en que los proyectos letrados latinoamericanos han sido cuestionados de raíz, ${ }^{3}$ como que el tipo de lector que propicia nuestro entorno audiovisual podría ser resistente al tipo de lectura profunda que exige la literatura. Los escritores, los críticos, las editoriales, la academia, el público, los medios de comunicación responden de distintas maneras a estos cambios culturales. Mi objetivo en este artículo es plantear algunas interrogantes en torno a estos actores de la crisis del paradigma de lo literario en el siglo XxI.

LOS ESCRITORES: ENTRE LA IMPRENTA, LA ORALIDAD SECUNDARIA ${ }^{4}$ Y EL HIPERTEXTO

Para reflexionar sobre la posición actual del escritor entre la galaxia Gütemberg y la galaxia electrónica dialogaremos con las ideas de la venezolana Ana Teresa Torres (Caracas, 1945), que sintetizan con justicia los problemas del escritor(a) latinoamericano(a) en el siglo xxi, entre los cuales tenemos: el hecho de escribir en esta época, la pérdida de espacio sociocultural de la literatura, la presencia de los medios y la informática y el mercado editorial actual.

Comenzaré por la actitud distinta del escritor(a) de hoy frente al hecho mismo de escribir: Tengo la creencia, quizás infundada, pero que de alguna manera quedó en mí a partir de
la lectura de los clásicos, de que hubo un tiempo, un "antes” impreciso, en el cual el
escritor escribía para la eternidad. Sin ir tan lejos como a las tragedias griegas, la literatura
medieval o el Siglo de Oro Español, obras como La búsqueda del Tiempo Perdido, La
Guerra y la Paz, La Montaña Mágica parecieran monumentos literarios, construidos con
la lentitud y la perfección que sólo el deseo de ser inmortal podría sostener, y dirigidos
a lectores que los leerían por los siglos de los siglos. Pienso hoy que expresaban también
la confianza de la humanidad en su perdurabilidad, de la cual la historia de la literatura
era un testimonio.(“El escritor ante” 68)

\footnotetext{
${ }^{2}$ En Las reglas del arte. Génesis y estructura del campo literario, Pierre Bourdieu destaca las características del campo literario visto como un campo de fuerzas cuyas reglas de funcionamiento se formulan en su interior mismo. La autonomía radical del campo literario es una herencia del siglo xIx, y supone el mito de la libertad absoluta del artista en tanto creador libre de toda constricción social o política, las instancias institucionales de consagración —académicas, editoriales, público ilustrado-, y la oposición encarnizada entre distintas estéticas y entre éstas y el mercado como condición sine qua non para obtener el control del capital simbólico.

${ }^{3}$ Críticos pertenecientes a los Estudios Culturales, como John Beverley y Vicente Lecuna han desarrollado estos cuestionamientos en sus trabajos.

${ }^{4}$ Respecto al libro y la lectura, Martín Barbero (“Los nuevos modos...” 20) realiza el siguiente planteamiento: “(...)¿Cómo pueden entenderse las problemáticas del libro y la lectura en América Latina sin plantearse la profunda compenetración —la complicidad y complejidad de relacionesentre la oralidad que perdura como experiencia cultural primaria y la "oralidad secundaria" que tejen y organizan las gramáticas tecnoperceptivas de la radio, el cine, la televisión y el video? (...)”
} 
El escritor o la escritora tienen que enfrentarse en estos momentos a una modificación sustancial del campo literario, en el cual la mirada canónica que convirtió al arte y la literatura en una suerte de sustituto secular de la teología (Bourdieu 168), es puesta en cuestión desde la condiciones históricas mismas. Vivimos un tiempo "exento de la discursividad histórica” (Salabert 16), es decir, un tiempo en el que los acontecimientos y la propia experiencia escapan de la sintaxis y la coherencia del relato de la historia y del relato literario, y se convierten en un simple "pasar sin trascender" (Salabert 17), que se consume en la vorágine audiovisual que constituye el mundo actual. La literatura, contemplada en tanto palabra hecha para la trascendencia y la duración, debe conformarse con un lugar más modesto y luchar por su perdurabilidad como práctica una vez que las grandes utopías letradas de la modernidad latinoamericana han sido puestas en entredicho: ya la literatura no es vista como manifestación y parte sustantiva de la identidad nacional, tampoco como una estrategia en contra de la alienación propiciada por la cultura de masas o como una instancia privilegiada de resistencia político-social. Por otra parte, las sociedades modernas han creado las condiciones para que la literatura pierda importancia como práctica de elite:

A veces se recurre al tópico de que “antes” se leía más, lo cual deja de lado la realidad contundente de que nunca ha habido en la historia el número de lectores que hay ahora, y ello por una razón muy simple, como es que la alfabetización masiva es un fenómeno que no tiene más de cincuenta años en la historia de la humanidad, y eso en los países de alto desarrollo social. Sin embargo, la sociedad desarrollada presenta dos paradojas con respecto a la recepción de la literatura. La primera es que nunca se habían publicado tantos libros como ahora [...]. En su multiplicación asombrosa, el libro parece sufrir el fenómeno de la saturación y la sobre-información que termina por banalizarlo [...] De este tema de la banalización de la información, algunos cineastas han extraído escenas inolvidables; valga la referencia a la cultura audiovisual porque en ella estamos inmersos, y plantea la segunda paradoja, o si se quiere la sorpresa de la historia, en el sentido de que precisamente, cuando una población mayoritaria tuvo acceso a la lectura y al tiempo libre para ejercerlas, por efecto de las mismas transformaciones sociales y económicas que lo permitieron, se produjo una cultura audiovisual que avasalló la cultura verbal. Utilizo la palabra avasallar porque los escritores, lo confesemos o no, nos sentimos un poco arrinconados por el mundo de la imagen. De ninguna manera me sitúo en la posición de adscribir a la literatura la belleza y el valor, dejando para el cine y la televisión y/o algún otro medio audiovisual lo vulgar y espúreo; ni me parece cierta la afirmación de que solamente la palabra contiene la posibilidad de suscitar en los hombres la imaginación, la fantasía o la evocación. Pienso que el siglo xxi exigirá del escritor profundizar una tendencia que ya de hecho ocurre, y es verse a sí mismo como uno de los posibles tipos de creador, cultivado y honrado por minorías que quieren seguir disfrutando del poder de la palabra, pero nunca más ese ser casi divino que poseía el secreto de inventar el mundo. (Torres, "El escritor ante" 69-70)

El avasallamiento de la cultura verbal por la visual va incluso más allá del problema del valor del texto literario de acuerdo a cualquier escala ideológica y estética. Aunque el número de potenciales lectores ha crecido, la competencia audiovisual por su propia naturaleza quita espacio a la literatura. La lectura, así sea en la propia lengua, es la operación intelectual más compleja que existe pues implica un esfuerzo de traducción de 
un conjunto de signos abstractos en sus distintas significaciones, y requiere de una larga preparación y del cultivo paciente de determinadas aptitudes. Pero, además, los modos de leer literatura contradicen abiertamente el tipo de lectura que nuestro entorno audiovisual e informático estimula. Los nacidos después de 1960 hemos vivido en un contexto, que los jóvenes y los niños de hoy enfrentan con todavía mayor intensidad, en el que nuestra manera de enfrentarnos al mundo y de "leer" ese mundo tiene que ver con la mirada errática, trashumante, acostumbrada a la intensidad y modificaciones constantes de la imagen televisiva, cinematográfica, fotográfica y publicitaria, mirada potenciada de manera abrumadora por la lectura en el ciberespacio, que privilegia la velocidad, la mirada rápida y los saltos de una página “web” a otra. Lo único en que se parece la lectura de literatura a las sesiones con Internet es que pueden absorber la atención hasta tal punto que provocan comentarios idénticos respecto al ensimismamiento y la soledad en la que sumergen al individuo. ${ }^{5}$ Pero las interrogantes sobre la relación hipertexto-literatura no acaban aquí. Teóricos como George Landow adelantan una actitud de celebración respecto a los cambios que traerá el hipertexto tanto en la literatura como en el conocimiento. En primer lugar, asume que el libro — literario o no— en sí mismo implica una visión del mundo quimérica: linealidad, integridad, coherencia, terminación (131-132), en franca contradicción con nuestra experiencia y los caminos del pensamiento. En segundo lugar, Landow postula que el hipertexto pone en entredicho ciertos supuestos básicos de la escritura literaria: los derechos de autor, la estabilidad del texto literario, la duración definida y el papel del lector no sólo como productor activo de significados sino como escritor él mismo (116).

En cuanto al cine y la televisión, tradicionales enemigos de la lectura según sus críticos, entran en juego con una ventaja sustancial frente a la literatura: implican un esfuerzo de decodificación menor — dependiendo desde luego la obra en cuestión — que el que exige el texto literario convencionalmente conocido como tal. Decir que la televisión es un vehículo de alienación y destrucción cultural es un anacronismo, pero más allá de eso hay que reconocer que la fascinación "hipersensorial” que produce en el espectador, le permite obtener información, conocimiento y diversión de manera más expedita y sencilla que a través de la lectura literaria o de cualquier otro tipo de material (Olaechea 137). Y tanto la televisión como el cine se adaptan mucho mejor a las condiciones de las grandes ciudades, en las que el tiempo escasea, la soledad no deseada se ha acentuado y la cultura ha asumido un grado de espectacularidad sin precedentes. Respecto a este asunto, afirma Martín Barbero en su análisis sobre Adorno y Benjamin:

\footnotetext{
${ }^{5}$ Juan B. Olaechea en El libro en el ecosistema de la comunicación cultural (18) comenta que según Marshall McLuhan la imprenta condujo a un conocimiento lineal, abstracto y desconectado de la realidad y fomentó la fragmentación de la sociedad al producir un tipo de hombre solitario, desgajado de las corrientes culturales de la comunidad. Por su parte, la comunicación escrita provoca una actividad unidimensional que limita la multisensorialidad. Por fortuna, apunta McLuhan, los medios de comunicación nos devuelven a nuestra situación primigenia y sinestésica. Esta posición, por cierto, es muy parecida a la de Beverley y Lecuna acerca del poder colonizador de la escritura sobre la oralidad. Lo sorprendente, es que Internet, sólo comparable a la entrada de la imprenta en el mundo y con la ventaja de haberse expandido en un tiempo récord, produce el mismo ensimismamiento que la literatura. Cosas del capitalismo tardío...
} 
(...)para la razón ilustrada la experiencia es lo oscuro, lo constitutivamente opaco, lo impensable. Para Benjamin, por el contrario, pensar la experiencia es el modo de acceder a lo que irrumpe en la historia con las masas y la técnica. No se puede entender lo que pasa culturalmente en las masas sin atender a su experiencia. Pues a diferencia de lo que pasa en la cultura culta, cuya clave está en la obra, para aquella otra la clave está en la percepción y el uso. Benjamin se atrevió a decir esto escandalosamente: “A la novela la separa de la narración el hecho de estar esencialmente referida al libro [...]. El narrador toma lo que narra de la experiencia, de la propia o de la que le han relatado. $Y$ a su vez lo convierte en experiencia de los que escuchan su historia. El novelista en cambio se mantiene aparte. La cámara natal de la novela es el individuo en su soledad”. Benjamin se da entonces a la tarea de pensar los cambios que configuran la modernidad desde el espacio de la percepción ... [...] (De los medios 62-63).

[...] La nueva forma de percepción es por el contrario colectiva y su sujeto es la masa "que sumerge en sí misma la obra artística”. Benjamin tiene conciencia de lo escandaloso de su proposición y nos advierte que ese modo de participación artística no tiene ningún crédito [...]. Y es que se necesitaba sin duda una sensibilidad bien desplazada del etnocentrismo de clase para afirmar la masa como matriz de un nuevo modo "positivo" de percepción cuyos dispositivos estarían en la dispersión, la imagen múltiple y el montaje. Con lo que se estaba afirmando una nueva relación de la masa con el arte, con la cultura, en la que la distracción es una actividad y una fuerza de la masa [...] Una masa que "de retrógrada frente a Picasso se transforma en progresista frente a Chaplin.” El espectador de cine se vuelve “experto”, pero de un tipo nuevo en el que no se oponen sino se conjugan la actitud crítica y el goce. (De los medios 67)

Sin duda, el análisis de Martín Barbero es plausible si atendemos precisamente a las formas de percepción del mundo que responden al auge de la cultura de masas facilitada y producida por los dispositivos tecnológicos desarrollados en el siglo xx, y si atendemos al hecho concreto de que la llamada cultura de masas explota el gozo de lo conocido y de lo sensible, en lugar de propiciar el distanciamiento imprescindible para el disfrute de lo que llamamos convencionalmente literatura y "gran arte”. Pero la actitud de Martín Barbero es si se quiere ambigua respecto a la literatura. Por un lado, afirma que la cultura letrada no puede seguir insistiendo en la centralidad del libro y de la literatura puesto que no responden a las necesidades culturales mayoritarias; e insiste también en que la lectura de literatura es una práctica que obedece a las exigencias burguesas de retraimiento, distancia y soledad, y utiliza al libro como instrumento fundamental en medio de un entorno oral (véase nota 4). Pero, por otro lado, exalta en Walter Benjamin su gusto por las literaturas marginales - como la de Charles Baudelaire - en tanto muestra de una conciencia especialmente lúcida del cambio histórico en relación con la visión y vivencia de la ciudad (Martín Barbero, De los medios 62-63). Pero, si partimos de esta ambigüedad, quizás aparente, podríamos hallar una razón para seguir escribiendo en esta época: la literatura, en tanto producto cultural basado en el lenguaje, es capaz de entender lo que otros discursos — audiovisuales, disciplinarios, etcétera — no han podido captar plenamente. Y no se trata de una postura romántica o de una exaltación de la palabra por sobre otras manifestaciones. Se trata, simplemente, de darle a la literatura el sitial que tiene en una época que considera que el lenguaje es central para entender las problemáticas socioculturales y políticas actuales: 


\begin{abstract}
Sabemos que el lenguaje, al nombrar, recorta la experiencia en categorías, segmenta la realidad mediante nombres y conceptos que delimitan unidades de sentido y de pensamiento. La experiencia del mundo que verbaliza el lenguaje depende del orden semántico que moldea esa experiencia en función de un determinado patrón de inteligibilidad y comunicabilidad de lo real y lo social. El modo en que cada sujeto se vive y se piensa está mediado por el sistema de representación del lenguaje que articula los procesos de subjetividad a través de formas culturales y de relaciones sociales [...]. (Richard, "Feminismo" 734)
\end{abstract}

Es en este sentido que la literatura, o cierta literatura para ser más exactos, es capaz de ofrecer visiones y acercamientos que otros discursos no son capaces. Y es que me parece que los ecos de la herencia baudeleriana continúan: la literatura olfatea y constituye la emergencia de nuevas "estructuras del sentimiento", es decir, de nuevas configuraciones ideológicas y simbólicas que surgen de la vivencia misma de los sujetos en la sociedad. ${ }^{6}$ Por esta razón, escritoras como Ana Teresa Torres se rebelan en contra de una concepción de la narrativa como la producción de historias entretenidas para un público que las despachará y olvidará rápidamente (Torres, "El escritor ante” 72). No otra es la actitud de muchos de los escritores actuales en América Latina: Carmen Boullosa (México), Diamela Eltit(Chile), Edgardo Rodríguez Juliá (Puerto Rico), Ricardo Piglia (Argentina), Milagros Mata Gil (Venezuela), Evelio Rosero Diago (Colombia), Jesús Díaz (Cuba), Sergio Ramírez (Nicaragua), por sólo mencionar unos pocos, apuestan por una escritura que asume su dificultad como una posibilidad de apertura a nuevos terrenos de significación y de entendimiento. Lo mismo podría decirse, desde luego, de los poetas.

La literatura ha sido y es una práctica minoritaria. Pero lo minoritario no es necesariamente negativo, a menos que se siga al pie de la letra una concepción hiperdemocrática y premoderna que comenzaría dejando afuera no sólo a la literatura sino a todo el conocimiento producido por las minorías académicas, científicas y tecnológicas... y lo que es tan o más grave, a todas las minorías étnicas, sexuales o políticas que no respondan a la sensibilidad mayoritaria. Es cierto que la cultura de masas propicia nuevas maneras de verse, integrarse y pensar en el mundo, pero también se sabe que muchas de las formas contemporáneas de la cultura de masas provienen precisamente de la literatura y del "gran arte", es decir, de prácticas producidas y entendidas por minorías. El melodrama telenovelesco y el cine le deben a la narrativa tanto como a nuestras formas de vernos socioculturalmente y a los dispositivos tecnológicos. Si Baudelaire supo entender la nueva ciudad, el realismo literario nos enseñó, en parte, a contarla y vivirla. Como dice Beatriz Sarlo:

Una cultura también se forma con los textos cuyo impacto está perfectamente limitado a una minoría. Afirmar esto no equivale a elitismo, sino a reconocer los modos en que

\footnotetext{
${ }^{6}$ Dice Raymond Williams: “El término resulta difícil; sin embargo, 'sentir' ha sido elegido con la finalidad de acentuar una distinción respecto de los conceptos más formales de 'concepción del mundo’ o ‘ideología’. No se trata solamente de que debamos ir más allá de las creencias sistemáticas y formalmente sostenidas, aunque siempre debamos incluirlas. Se trata de que estamos interesados en los significados y valores tal como son vividos y sentidos activamente; y las relaciones existentes entre ellos y las creencias sistemáticas o formales, en la práctica son variables (...)” (154-55).
} 
funcionan las culturas, como máquinas gigantescas de traducción cuyos materiales no requieren aprobar un test de popularidad en todo momento. Aunque, a través de caminos que sólo conoce Dios, esos materiales pueden ser populares en el futuro. (39)

Otro de los problemas que tienen que enfrentar los escritores y escritoras, precisamente por su impacto minoritario, es el del mercado editorial. El riesgo de dedicar meses y años a una actividad cuya máxima recompensa puede ser una edición de mil ejemplares y el reconocimiento de unos pocos, es el pan de cada día de la mayoría de los escritores. Muchas de las actividades con las que antes sobrevivían - docencia, periodismo, conferencias- están en otras manos, están reñidas con la época, o requieren de una calificación universitaria que lo que hace es quitar tiempo para escribir. Las grandes editoriales se inclinan por Paulo Coelho o Laura Esquivel:

El mundo editorial ha dejado de ser ya ese nostálgico taller artesanal en el que convivían arriesgados editores, tipógrafos anarquistas y escritores bohemios, con frecuencia centro de tertulias y de publicación de textos revolucionarios, para convertirse en el mundo de las transnacionales del libro, cuyos propietarios rara vez leen lo que publican, y el autor es, lo quiera o no, una imagen que forma parte de ese mundo y sobre quien recae la caducidad de la imagen publicitaria. Ni el escritor más purista puede verse libre de ello, si desea ser publicado. (Torres, "El escritor ante" 68-69)

Tampoco la fidelidad a los objetivos estéticos tiene el trasfondo heroico de otras épocas: la caída de las utopías, la cultura de masas, la enciclopédica sabiduría sociológica de Pierre Bourdieu, la caída de la posición del escritor como conciencia crítica de la sociedad, las nuevas tecnologías y los afanes antiestéticos de los Estudios Culturales no han pasado en balde. Quizás por eso, la literatura de las últimas décadas obedece a otra dinámica, si la comparamos, por ejemplo, con la visión mesiánica y modernizante que adelantaron los escritores del "boom":

“Compensación” quizás sea la mejor palabra para definir la demanda a la que respondía la literatura latinoamericana hasta las dictaduras de los años setenta: desde las proclamaciones eufóricas y, triunfantes, de Carlos Fuentes y Vargas Llosa sobre cómo la exitosa ficción del boom ofrecía un remedio (prefiero llamarlo consuelo) para el atraso material del continente, hasta los desocultamientos de la "verdad censurada" llevados a cabo por el naturalismo testimonial o por la novela-testimonial o por la novela-reportaje, la literatura hegemónica de ese período se legitima a partir de una estrategia compensatoria. Si hoy no hay que desocultar - tanto porque la censura ha sido reemplazada por un régimen de sobreexposición y saturación de los signos, como porque los desvelamientos de las ideologías han sido ya completamente absorbidos por la ideología en cuanto talla literatura se ve obligada a replantearse su lugar en una época postcompensatoria. Algo suena a pérdida aquí: nos habíamos acostumbrado a pensar, orgullosos, en la literatura como portavoz privilegiada de un discurso de identidad, sea él continental, nacional, o individual; o aun, en buen estilo ilustrado, como desenmascaradora de los mitos oficiales. El lector de Joao Gilberto Noll, de Tununa Mercado, de Gonzalo Contreras, de Diamela Eltit —algunos de los ficcionistas que han sabido pensar la crisis de la compensaciónse da cuenta de que algo ha cambiado profundamente aquí. (Avelar 42) 
Y ese algo que ha cambiado profundamente no es sólo el concepto del rol sociocultural de la literatura, sino también sus condiciones de producción, recepción y difusión. Pondré un caso extremo. Pensemos en las mujeres escritoras que no responden al éxito editorial masivo y que son objeto de varias discriminaciones: las del mercado transnacional, las de la crítica literaria tradicional, la de los Estudios Culturales en su rechazo al carácter hegemónico de las prácticas letradas y las de cierto sector de la crítica feminista:

\begin{abstract}
No son mujeres las propietarias de los grandes consorcios editoriales ni las dueñas de la crítica y el poder en los medios literarios. Por el contrario, son ellas las que han creado muchas editoriales marginales — castigadas por llamarse feministas — y luchado por darle visibilidad a la obra de escritoras desconocidas. Pelear con las estrellas no les interesa; las dejan en su opción de brillar solitarias. Lo que les importa es apropiarse de espacios tanto tiempo negados y usurpados por la crítica de visión masculina.(Torres, "Balza y" 50)
\end{abstract}

De manera contradictoria, muchos escritores y críticos se sienten disminuidos por el éxito de mercado de algunas escritoras y apuntan sus ataques hacia toda mujer que escriba. Olvidan que cantidades de escritoras sólo acceden a un reconocimiento muy pequeño y relativo que a veces no pasa de las fronteras de sus países o de un público internacional minoritario. Si el mercado segrega a escritoras, y también escritores, que no tienen las características para hacer un libro exitoso, la crítica lo hace por la simple voluntad de homologar éxito con mediocridad, y mediocridad con la pertenencia a un sexo o a una cultura determinada. Pero además,

[...] No entramos en la marca favorita de un escritor no europeo: la estética del sufrimiento. ("De novela, mercado" 18)

Para colmo, los venezolanos carecemos de otra marca privilegiada: el garciamarquismo y el isabelallendismo. ("De novela, mercado" 19)

[...] La mayor parte de la literatura que se está escribiendo actualmente entre nosotros es urbana, y la mayoría de los problemas que nos interesan no son para nada realmaravillosos sino muy terrestres y pedestres. ("De novela, mercado" 20).

El escritor y la escritora latinoamericana enfrentan, pues, la existencia de una crítica y de un público europeo y norteamericano que exige de la literatura latinoamericana la dosis de "exotismo" y "naturaleza" que parecen no hallar en sus propias culturas europeas o norteamericanas. Los retos del escritor y la escritora en América Latina atienden pues a una modificación del campo literario en tanto instancia de legitimación del ejercicio de la escritura. Muy difícilmente se podría pensar hoy en día en que la "salvación” del ejercicio de la literatura pueda hacerse tratando a toda costa de apelar a los fueros de la genialidad, la individualidad creadora rebelde, la cultura universal o el arte como una religión secularizada. Creo que el escritor o la escritora actual apela al ejercicio de la literatura en tanto oficio (dimensión frecuentemente olvidada por cierta crítica) y a la existencia de múltiples públicos entre los cuales algunos continúan obteniendo determinadas satisfacciones de la literatura, tanto de la llamada literatura de elite como de la llamada subliteratura (que obtiene éxitos resonantes como los de Paulo Coelho, la adaptación a 
novela hecha por Michael Chrichton de Jurassic Park, de Steven Speilberg, o el fenómeno infantil-juvenil de Harry Potter). Eso sí, sería ingenuo pensar que los escritores(as) puedan constituir el mercado como su panacea: el mercado masivo editorial está demasiado controlado por instancias que hacen casi imposible que un escritor venezolano pueda obtener el éxito de los españoles Lucía Etxebarria o José María Mañá, el joven narrador de Historias del Croner.

\title{
QUIÉN LE TEME A LA LITERATURA O DE LA CRÍTICA ANTIESTÉTICA
}

Sorprendentemente, ha sido del seno de la crítica literaria del que han surgido los cuestionamientos teóricos e ideológicos al papel de la literatura en la cultura. Todos los fundamentos de la existencia misma de la literatura han sido cuidadosamente desmontados y removidos en sus cimientos. Podría decirse que el sólido aparato teórico de la crítica literaria contemporánea, latinoamericana o no, se ha desarrollado a partir de desacralizar al texto literario hasta un punto tal que, como afirman Beatriz Sarlo (36) y Jean Franco (219), en los momentos actuales sería muy difícil — sin ser acusado de conservador, elitista, esteticista o romántico incurable-plantearse el problema del valor y la pertinencia de una práctica textual frente a otra. Veamos algunos de los caminos que ha tomado la discusión actual sobre el problema de los valores estéticos y sobre el objeto, las implicaciones ideológicas y los instrumentos teóricos-metodológicos de la crítica. Comenzaré por Beatriz Sarlo y su visión acerca de los valores y el carácter específico de los textos literarios:

\begin{abstract}
Aprendimos nuestra lección. Profesamos el relativismo como piedra de toque de nuestras convicciones multiculturales. Pero las consecuencias del relativismo extremo son arrojadas ante nuestros ojos por los antirrelativistas de la derecha, cuando nos acusan de destruir a la literatura junto con el canon occidental, masculino y blanco.

Para entrar en este debate libres de una mala fe moralizante, deberíamos reconocer abiertamente que la literatura es valiosa no porque todos los textos sean iguales y todos puedan ser culturalmente explicados, sino, por el contrario, porque son diferentes y resisten una interpretación sociocultural ilimitada. Algo siempre queda cuando explicamos socialmente los textos literarios y ese algo es crucial. No se trata de una esencia inexpresable, sino de una resistencia, la fuerza de un sentido que permanece y varía a lo largo del tiempo. Para frasearlo de otro modo: los hombres y las mujeres son iguales; los textos no lo son. La igualdad de las personas es un presupuesto necesario (es la base conceptual del liberalismo democrático). La igualdad de los textos equivale a la supresión de las cualidades que hace que sean valiosos. (Sarlo 36)
\end{abstract}

Por su parte, Jean Franco expone los caminos que ha tomado el debate sobre el objeto y la finalidad de la crítica:

Hoy en día el corpus incluye la cultura de masas y el concepto de literatura se disuelve: por un lado, desaparece en el concepto mercantil de cultura y, por otro, se transforma en una instancia de la problemática de la significación. La crítica literaria parece haber perdido su objeto o por lo menos el objeto que antes era descrito como "autónomo". 
La solución por lo menos en Estados Unidos, ha sido extender el campo hacia los estudios culturales que parten de la propuesta al parecer razonable de que la cultura no se circunscribe a la literatura, el arte o la música clásica. La cultura de masas es la cultura de la mayoría; la música rap ha introducido en la práctica de la poesía a miles de personas, la discusión de la telenovela es parte de la cultura diaria de muchas personas y los mismos académicos son tan susceptibles al carisma del soap opera star como cualquier vecino del barrio.

Los estudios culturales, en sus primeras manifestaciones, rechazaban la actitud pesimista hacia la cultura de masas de la escuela de Frankfurt y ahora parecen obedecer a un proyecto más democrático, aunque corren el peligro de un pluralismo igualitario que juzga todo como de igual valor.

De hecho la cuestión del valor es fundamental en el momento actual. Algunos críticos, en especial los latinoamericanos de Estados Unidos, han encontrado la institución demasiado elitista, por lo que han tratado de fundamentar el valor de los textos en una ética de responsabilidad hacia las clases subalternas [...]. (218-19)

Por último, veamos cómo define Grínor Rojo el pluralismo teórico-metodológico de los Estudios Culturales frente a los límites disciplinarios, a los que responden la crítica literaria y otras disciplinas:

Por supuesto, esta indeterminación de los estudios culturales con respecto a sí mismos no es casual. No es que estos estudios (o estos estudiosos) no sean capaces de darse a sí mismos un objeto o unos procedimientos metodológicos, lo que pasa es que no quieren hacerlo. Porque los estudios culturales entran a hacer su trabajo en la imposibilidad, cuando no la indisposición deliberada, por parte de las disciplinas del humanismo moderno, para dar cuenta de una agenda de asuntos que cada vez las presionan con más impaciencia. Es evidente que esas disciplinas tradicionales no han querido abrir los ojos a tales presiones. No sólo la crítica literaria, sino también la historia, la antropología, la filosofía, la sicología, etcétera, son todos quehaceres especializados que trazan, cada uno con su propio sistema de pesos y medidas, el perímetro de su pertinencia o, para decirlo con más precisión aún, su política de inclusiones y de exclusiones. En conjunto, esas políticas forman o formaron la política de las inclusiones y exclusiones de las llamadas humanidades o ciencias humanas durante los últimos trescientos o más años de la historia de Occidente, la que no era inmotivada. Por detrás de ella, lo que se alzaba era una cierta idea del hombre. Esa idea del hombre era la que autorizaba y desautorizaba, la que protegía y excomulgaba. En el último análisis, lo que los estudios culturales están combatiendo es la legitimidad (y, por lo tanto, la autoridad) de ese constructo ideológico básico, el mismo que respalda aún las prácticas del humanismo contemporáneo. (77-78)

Vemos dos cambios básicos respecto a los debates anteriores sobre la crítica literaria latinoamericana. El primero atañe al objeto mismo de estudio: hasta las últimas décadas estaba perfectamente claro que la crítica tenía un objeto de importancia central en la cultura, la producción literaria. Lo que había que discutir eran los enfoques teóricos, metodológicos e ideológicos desde los cuales se debía enfrentar el análisis de dicho objeto. Ahora el objeto y la idea de un enfoque teórico-metodológico coherente son los blancos mismos de la discusión. En este sentido, el latinoamericanismo ha sufrido un vuelco al tener que orientarse por derroteros esencialmente distintos a los que le eran propios: la nación, las diferenciaciones entre alta cultura, cultura popular y cultura de masas, la 
literatura, los proyectos educativos letrados han sido objeto de un radical replanteamiento. No es poca la ganancia si consideramos la productiva trayectoria de la teoría literaria, que permite acercarse con instrumentos altamente sofisticados a textos pertenecientes a otros discursos, y abrir un espacio de diálogo que retaría al especialismo académico y a los restos de elitismo del humanismo contemporáneo. No obstante, el norte de los Estudios Culturales parecería ser distinto, pues más bien en ciertos casos extremos se trataría de hacer de la cultura un mar de textos indiferenciados, tal como lo plantea Sarlo, con lo cual la literatura, práctica central de la cultura occidental letrada, no sería considerada un tipo de texto que requiere de un enfoque distinto al de otros. Por desgracia, cierta tendencia influyente de los Estudios Culturales parte de esta premisa y de una suerte de obsesión ideológica en contra de la modernidad ilustrada que no puede menos que llamar la atención (proviene de minorías radicadas en los Estados Unidos, que han convertido a América Latina en su espacio de resistencia a la modernidad). ${ }^{7}$

Por esta razón, en el discurso actual que cuestiona el lugar de la literatura hay una inclinación que me parece peligrosa políticamente hablando. ${ }^{8} \mathrm{Y}$ es que el que algo sea hegemónico —en el sentido concreto de práctica letrada - no puede convertirlo inmediatamente en un objeto de condena ideológica. Desde una perspectiva radical se puede llegar a meter en el mismo saco la cura del sida (que forma parte de la medicina, práctica letrada elitesca y hegemónica) —y el fascismo; el patriarcado y el discurso lógico- racional (toda la crítica al falologocentrismo del feminismo de inspiración lacaniana es una protesta en contra de la existencia misma de la ciencia y del lenguaje

\footnotetext{
${ }^{7}$ Un excelente ejemplo de esta afirmación lo encontramos en ciertas tendencias del feminismo: "También dentro del feminismo opera este ideologema del cuerpo (realidad concreta, vivencia práctica) que soporta la fantasía de una América Latina animada por la energía salvadora del compromiso social y de la lucha comunitaria, cuyo valor popular y testimonial es juzgado políticamente superior a cualquier elaboración teórico-discursiva: 'fuera de los ámbitos oficiales de una cultura centrada en la escritura y la disquisición filosófica, en el retazo de la arpillera se cuenta una experiencia personal con el hilo y la aguja para inscribir la memoria e hilvana a la mujer en su dolor'. Esta reubicación de la mujer por el lado de la inmediatez del hacer (vivencia, acción, experiencia) con sus emblemas domésticos del 'cocer, bordar o cocinar' hace juego con la imagen de Latinoamérica y de las prácticas de las mujeres latinoamericanas como lo otro radical de la academia norteamericana. Si bien es cierto que las batallas descolonizadoras, las luchas populares y las convulsiones dictatoriales de América Latina han gestado texto y conocimiento fuera del canon libresco, en los bordes informales y subversivos de la cultura extra-académica e institucional, emblematizar ese cuerpo de experiencia como la única verdad del feminismo latinoamericano (su verdad primaria y radical, por antidiscursiva) puede llegar a confirmar el estereotipo de una “otredad” romantizada — en tanto popular — por la intelectualidad metropolitana y dejar así intacta la jerarquía representacional del centro que sigue hegemonizando todas las mediaciones conceptuales del 'pensar”" (Richard "Feminismo" 738).

${ }^{8}$ ¿Para qué el feminismo, el antietnocentrismo, el pacifismo, la tolerancia religiosa si finalmente son manifestaciones propias del imperial proyecto moderno europeo, como diría cualquier talibán afgano que se respete, haya apedreado a una adúltera y haya destruido una estatua de Buda? ¿El hecho de que culturas como la afgana hayan sido sometidas a las intervenciones interesadas de la Unión Soviética y Estados Unidos da pie a justificar su reacción en tanto rebelión en contra de la modernidad? ¿Cómo esta vivencia colectiva puede combinarse con lo que propone Martín Barbero acerca de las prácticas libertarias de las mujeres, las minorías y los sectores populares?
} 
racional, lenguaje que por cierto impulsó a todos los grandes movimientos feministas de la historia); y el imperialismo con la secularización que ha permitido que las mujeres y las minorías sexuales, religiosas y étnicas tengan derechos en tanto ciudadanos. ${ }^{9}$ Parte del discurso intelectual actual es culposo y está intentando suplir su ausencia de influencia social con un populismo que no aclara en todas sus dimensiones los alcances y sustento de su práctica desde el punto de vista político, ético, académico y cognoscitivo. Se lanza a la literatura por la ventana en nombre de un sociologismo estrecho que, si fuese fiel a su propuesta de fondo, se daría cuenta de que todas las configuraciones culturales viven de su propia "illusio", como diría Pierre Bourdieu (485). Es decir, crean sus propias justificaciones y formas de creación, difusión y recepción que las hacen válidas dentro de un contexto dado: la religión, las tradiciones populares y los comportamientos sociales funcionan con esta dinámica. Además, llama la atención que en una época que está convencida de los poderes del lenguaje, se desee obviar lo que implica el quehacer estético en tanto hecho precisamente de lenguaje.

Paradójicamente, los Estudios Culturales, con sus minuciosos desmontajes del prestigio estético, se hermana con el mercado y sus mecanismos de exclusión. La literatura es minoritaria y ha tenido demasiada influencia en el mundo moderno: vamos a rechazarla en nombre de lo políticamente correcto para las mayorías o para determinados sectores calificados de subalternos; sustituyamos "políticamente correcto" por "aceptable y divertido" y "demasiada influencia” por "poca influencia” y encontraremos una notable coincidencia. Por supuesto, se puede argumentar que defiendo a la literatura porque temo perder mis privilegios como profesora e investigadora. La respuesta a esto es que coincido plenamente con los Estudios Culturales, con Martín Barbero y García Canclini en que la cultura no puede reducirse a la cultura de elites, en que es necesario abrirse a la posibilidad de entender configuraciones simbólicas diversas, y de hecho lo hago en mi trabajo. Lo que no termino de entender bien es la incomprensión sobre el carácter sociológicamente definido e importante de eso que llamamos estética en el mundo moderno. La distinción de Pierre Bourdieu, De los medios a las mediaciones, de Martín Barbero, Apocalípticos e integrados, de Umberto Eco, Culturas híbridas, de García Canclini, son intentos de comprensión de los mecanismos de inclusión y exclusión con el que los distintos sectores contemporáneos entienden sus prácticas sociales de ocio y disfrute sensible. No comprender la dimensión estética del mundo es como ignorar el poder de la religión porque se es ateo. Como actitud personal me parece bien, pero como postura crítica es una omisión cuestionable.

No se trata aquí de un problema de conservadurismo estético o de una teología secularizada, se trata de la importancia que tienen en nuestras sociedades las distintas formas de la narración — el cine y la telenovela — o la canción popular. El bolero le debe mucho a la estética romántica y modernista (en el sentido de modernismo como movimiento literario), y el cine y la televisión no terminan de saldar sus cuentas con la novela y el cuento, así como con el circo, el melodrama como espectáculo popular y otras manifestaciones (Martín Barbero, De los medios a las mediaciones 151-57). El gran éxito

${ }^{9}$ Véase el epílogo con respecto al profundo irracionalismo y espíritu reaccionario que tienen algunas críticas a la modernidad, el epílogo (201-29) de Imposturas intelectuales, de Sokal y Bricmont. 
telenovelesco de principios del siglo xxi es la telenovela colombiana Yo soy Betty la fea: la clásica historia del patito feo, mezclada con un feminismo reformista que aúpa los derechos de la mujer, una concepción melodramática sobre el bien y el mal y un humor popular y ácido a toda prueba, por no hablar del trasfondo shakespereano en el que titilan suavemente Romeo y Julieta o el clásico folletín decimonónico que atacaba las diferencias sociales en nombre del amor entre los protagonistas. ¿Cómo analizar un fenómeno de éxito masivo olvidando todas estas matrices literarias?

Quizás la crítica podría ir más lejos aún: la literatura, precisamente por esta capacidad de influir aunque sea de esta manera en el colectivo, es un bastión más de la hegemonía letrada sobre las culturas subalternas:

La subalteridad es una forma de identidad diferencial no ontológica: es decir, es el producto de relaciones sociales históricamente específicas. Lo que [Ángel] Rama descubrió en La ciudad letrada es que la literatura fue y sigue siendo en América Latina precisamente una práctica constitutiva de las elites - hipótesis adelantada en parte por Alejandro Losada en su trabajo sobre el romanticismo peruano. Aún en formas “progresistas" — para emplear la conocida consigna de los sesenta—, es quizás más parte del problema que de la solución. Las contradicciones entre literatura y cultura vernacular se hicieron menos agudas, pero de ninguna manera desaparecieron con las campañas de alfabetización introducidas por la Revolución Cubana o nicaragüense o el proyecto de los talleres de poesía de Ernesto Cardenal. Otra vez, la idea de alfabetización implica que una forma de cultura, la print culture, es necesaria para ejercer los deberes de un ciudadano o una ciudadana. Mientras tanto, como sospechaba [Antonio] Cándido, la mutación de la esfera pública causada por los medios audiovisuales conduce a un aplazamiento nuevo y progresivo de la idea de la literatura como un modelo o práctica formadora de identidad nacional y/o cívica. En este sentido, el fenómeno de la democratización representa el otro lado de la crisis de la literatura y de los estudios literarios latinoamericanos. En una sociedad realmente democrática, ¿qué es lo que garantiza la autoridad cultural de la literatura? Evidentemente sólo el uso que se hace de ella. (Beverley 29)

De algún modo he comentado y comentaré esta posición a lo largo del artículo. Pero en todo caso, lo que me interesa destacar es que si aceptamos que la narrativa, por ejemplo, no es un simple género literario sino una gramática del conocimiento y la percepción del mundo, nuestra propia herencia cultural y social nos obliga no sólo a revisar la literatura en tanto críticos sino a entender que un grupo de individuos — aunque la palabra individuo tenga resonancias contradictorias y complejas - se dedique a la escritura literaria. Hasta enemigos acérrimos de las concepciones salvacionistas y elitescas de la alta cultura como Martín Barbero y Pierre Bourdieu pueden decir cosas como éstas:

[...] Como ha demostrado Rezsler, la tesis de la decadencia del arte moderno no habla sólo de la estrechez de un marxismo vulgar, sino de un impasse de fondo en la teoría marxista ortodoxa. Claro que el razonamiento de Jdanov no es el de Lukács, pero el significado de la tesis y los objetivos políticos fueron los mismos. En ambos lo que se condena como asocial por individualista, o antisocial por burgués, es el experimentalismo: la capacidad de experimentar y desde ahí cuestionar las "pretensiones de realidad” que encubría el 
realismo. Realismo que es asumido como el gusto profundo y el modo de expresión de las clases populares. La paradoja toca fondo: la invocación al pueblo es sólo para oponer el conservadurismo de su gusto, "su buen sentido", a la revolución que está transformando el arte. Y la continuidad que se reclama con el pasado es "la continuidad con los valores culturales de la época burguesa socavados por los movimientos modernistas”. Se apela al pueblo pero en el sentido más populista y negativamente romántico: para exaltar como criterios básicos de la verdadera obra de arte la simplicidad y comprensibilidad por parte de las masas.(Martín Barbero, De los medios 25)

No hay mejor prueba de todo lo que separa la escritura literaria de la escritura científica que esta capacidad que le pertenece por derecho propio, de concentrar y condensar en la singularidad concreta de una figura sensible y de una aventura individual, que funciona a la vez como metáfora y como metonimia, toda la complejidad de una estructura y de una historia que el análisis científico tiene que desarrollar y extender muy laboriosamente. (Bourdieu 51)

Tanto Martín Barbero como Bourdieu entienden el papel que pueden tener el arte y la literatura al momento de abordar problemas tan espinosos como el cambio cultural, las nuevas matrices simbólicas y la percepción de las realidades históricas emergentes. Escojo a estos dos teóricos tan impermeables a cualquier divinización de la estética, para ejemplificar el sentido que puede tener hoy día estudiar las múltiples configuraciones culturales en las que vivimos, y que incluyen por supuesto a las minorías, y el sentido que puede tener escribir literatura, más allá y más acá del éxito de mercado y del endiosamiento del individuo. Se trata de entender que la literatura ha sido parte fundamental de nuestra herencia cultural. Si se exalta a los indígenas por querer defender su visión de mundo a todo evento, una visión de mundo que puede incluir perfectamente variables machistas y etnocéntricas, no veo por qué otros sectores sociales no tenemos derecho a examinar y aprovechar nuestra herencia cultural desde una perspectiva crítica que privilegie la historicidad misma de esa herencia. El único modo de estudiar literatura no es cantando loas al canon, excluyendo otras manifestaciones culturales o asumiendo una suerte de olímpica superioridad cultural de la práctica letrada. Es más, se puede estudiar literatura sin tenerle miedo al problema de los valores. Como dice Beatriz Sarlo:

El desafío es si podremos imaginar nuevos modos de considerar los valores, modos que (aunque parezca contradictorio) sean a la vez pluralistas, relativistas, formalistas y no convencionalistas. Una perspectiva relativista prueba que los valores varían según los contextos culturales. Según el relativismo deberíamos leer los textos en sus contextos y juzgarlos por las estrategias que emplean para resolver las preguntas que esos contextos consideran apropiadas. De este modo, la discusión de valores es siempre una discusión textualizada. (36)

[...] desde una perspectiva transcultural los valores son relativos en el espacio global donde las culturas son iguales (como los ciudadanos son iguales). Pero no todos los valores de una cultura (esto ya ha sido argumentado por Habermas), merecen la misma estima si se les considera desde contextos extraños a esa cultura. Los valores son relativos pero no indiferentes. Y para cada cultura los valores no son negativos desde el punto de vista intratextual. Las culturas pueden ser respetadas y al mismo tiempo discutidas. (37) 
La pertinencia de este planteamiento de Sarlo atañe al sentido mismo de escribir, leer y estudiar literatura: los valores estéticos e ideológicos implicados en la literatura pueden sin duda ser relativos desde múltiples ópticas, pero para nosotros, los que escribimos, leemos o estudiamos literatura, no son indiferentes. Mi cuestionamiento de fondo a los Estudios Culturales — en la versión de los departamentos de español norteamericanoses que en nombre de las prácticas culturales subalternas o no letradas, se nos está exigiendo que rechacemos discursos, perspectivas, visiones de mundo, que son importantes para un sector de la sociedad (y para otros, pero quiero ser lo más justa posible), del que formo parte sin complejos de culpa: sectores medios, letrados, profesionales y urbanos. Me siento heredera del sentido crítico de la modernidad y apelo a él para entender los horrores y sinsabores de las modernizaciones latinoamericanas, y el silenciamiento al que han sido sometidos las mujeres, los indígenas, los negros, los homosexuales y lesbianas, los pobres... En rigor yo misma pertenezco por lo menos a dos o tres categorías de subalternos. Pero en nombre de los horrores a los que éstos han sido sometidos, no se me puede exigir que lance por la ventana valores esenciales de mi cultura, y la estética es uno de ellos:

Los estudios literarios también han resentido la confusión generada por el proyecto de los Estudios Culturales de querer extender la noción de texto a la articulación semiótica de cualquier práctica social, sin ya atender la diferencia entre narración (volumen) e información (superficie), que separa lo directo de lo indirecto, la simbolización estética del trámite comunicativo. La crisis del paradigma de lo literario ha movido la interrogante —-formulada por Beverley_ de saber "qué pasaría cuando la literatura sea simplemente un discurso entre muchos” (Beverley, "Hay vida” 39), es decir, cuando se disuelva la frontera entre lenguaje cotidiano (instrumentalidad del lenguaje) y lenguaje poético (autorreflexividad y plurivocidad del signo). Es decir, cuando todo lo hablado y lo escrito se uniformen bajo el mismo registro banalizado de una mortal desintentificación del sentido, porque la palabra habrá dejado de ser teatro o acontecimiento para volverse simple moneda de intercambio práctico ya carente de todo brillo, fulgor o dramaticidad. Creo que la pregunta por el destino de lo estético-literario en cuanto voluntad figurativa de un signo estallado y plural que critica la masa comunicológica, también recae sobre la dimensión imaginativa del texto crítico, seriamente amenazada por una desapasionada lengua funcionaria que borra de sus trámites notificantes cualquier "placer del texto": cualquier emoción o destello aún ligados al tembloroso perfil de palabras sugerentes bellas o ineficaces. Palabras capaces de actuar su disconformidad de estilos frente al "cálculo del saber categorial que trata de atrapar la inaprensibilidad del quién de cada sujeto en el qué de sus funciones destituyendo — de paso- "la heterogeneidad de lo otro, el episodio inaudito del otro, todo lo que ese otro es cuando no sólo es vida útil, citándolo a comparecer en la categoría”(Galende 55).(Richard, "Intersectando” 358).

Por último, me queda agregar que cuando hablo de estética no estoy postulando un regreso a las fortalezas canónicas, sino una posibilidad de entender la propia cultura, modificarla, replantearla, confrontarla... y disfrutarla. En este sentido coincido con Walter Mignolo, quien propone:

(...) que los debates sobre la formación del canon se desarrollen tanto en los planos vocacional y epistémico como a través de las fronteras culturales. A nivel vocacional, un 
canon literario debería verse en el contexto académico (¿qué debería enseñarse y por qué?). A nivel epistémico, la formación del canon debería analizarse en el contexto de los programas de investigación, como un fenómenos que debe ser descrito y explicado (¿cómo se forman y se transforman los cánones?, ¿qué grupos o clases sociales se representan mediante el canon?, ¿qué esconde el canon?, etc). A nivel de las fronteras culturales, un canon debería considerarse como relativo a la comunidad y no como una relación jerárquica respecto a un canon fundamental, ni tampoco dentro de un modelo evolutivo en el que los ejemplos canónicos se convierten en el paraíso al que aspiran las literaturas y en medida de la organización jerárquica. (245)

¿POR QUÉ Y PARA QUE ESCRIBIR, LEER Y ESTUDIAR LITERATURA ${ }^{10}$ (FRAGMENTOS DE CONCLUSIONES)

a) Los escritores actuales han crecido, padecido y gozado el mundo audiovisual, y saben que la práctica de la literatura da una oportunidad — por su curiosa situación de hechura casi artesanal (no se requiere el despliegue tecnológico, monetario y el concurso de tanta gente como en el cine, la radio, la publicidad y la televisión) que al mismo tiempo es un objeto del mercado de bienes culturales - de proponer representaciones alternativas y desplazamientos simbólicos y culturales particulares. Dice Norma Alarcón, refiriéndose a las posibilidades de la autorrepresentación en la literatura escrita por mujeres:

El sujeto histórico que escribe surge dentro de los discursos conflictivos generados por las teorías de la representación, bien sean éstas jurídicas o simbólico/textuales. Cada una de ellas está gobernada por normas que se basan en distintos presupuestos, por lo que una chicana puede tener mejor suerte al autorrepresentarse o ser representada a nivel textual que a nivel legal en tanto chicana. Es decir, el texto jurídico es producido por la elite dominante (...) mientras que a la representación en el texto cultural le está permitido incluir representaciones generadas por ella misma.(Alarcón 127)

b) Si, como ya dije en líneas anteriores, la reflexión sobre el lenguaje es sustancial en los debates académicos actuales, no entender lo que significa la literatura como exploración de las virtualidades de la lengua puede ser contradictorio conceptualmente. No entender que los textos son distintos y sus condiciones de producción, difusión y recepción también, significa que perderemos una fuente de resistencia política e intelectual, un filón de conocimiento y reflexión críticos y una alternativa de placer.

c) Las minorías y los excluidos de todo tipo han hecho suya a la literatura como posibilidad de expresar una voz. Si bien Spivak (Beverley 37) tiene en parte razón cuando alude a que el subalterno no puede hablar desde la discursividad propia del hegemónico, es una falta de sentido histórico negar que la literatura ha sido testigo y parte activa de todas las contradictorias pulsiones modernas, en las que el racismo, el imperialismo y el machismo han sido atacados no sólo desde las víctimas de los países no europeos o no norteamericanos, sino también desde el centro mismo de la hegemonía. Y el feminismo, la tolerancia religiosa, el pacifismo, la aceptación de las diferencias sexuales y culturales, las rebeliones populares contra las elites en el poder, son la otra cara de la modernidad, o,

${ }^{10}$ Estas conclusiones serán sucintamente enumeradas porque forman parte de un trabajo mayor. 
para los más críticos, la consecuencia natural de sus intentos de homogeneidad. Además, el sentido actual de la cultura se define por la apropiación y no por la exclusión. Debemos seguir escribiendo mal o bien sobre el otro, correcta o incorrectamente desde el punto de vista político, así algunos críticos afincados en Estados Unidos como Beverley o Spivak se empeñen en cuestionar estos acercamientos. Además, los académicos que hablan en nombre de los subalternos parecen en ocasiones obviar las condiciones en que estos tienen que vivir en el mundo actual. Lo mejor y lo peor de la modernidad es que la propia cultura no es un destino: por eso hay tantas migraciones, hay tantas formas de resistencia cultural y tantas reivindicaciones sociales de las culturas subalternas en nombre de un ataque a la modernidad, pero también en nombre de algo tan occidental y secularizado como la libertad política, el rechazo a la xenofobia, la tolerancia religiosa y los derechos humanos (así sean hipocresías hegemónicas). Por fortuna, existen tantos escritores y formas de escritura, que tendremos siempre la oportunidad de acercarnos desde el lenguaje a todos los entrecruzamientos que constituyen la vida de la gente de nuestra época.

e) La literatura es una forma de vernos a nosotros mismos a través de la experiencia vicaria (Iser 58). No otra cosa hacen los espectadores de telenovelas y de cine. Creo injusto que Martín Barbero piense que la novela por su propia naturaleza libresca rechaza la experiencia, a menos que ésta se reduzca a formas expeditas y fáciles de consumo y de percepción sensibles. Como dice Idelber Avelar (42), la literatura actual examina las opciones posibles producto de la dialéctica literatura/experiencia. Toda la amplia gama de registros de la literatura latinoamericana de hoy obedece a una voluntad de hacer de la experiencia una posibilidad de reflexión más allá de la vivencia inmediata y olvidable que impone el estilo de vida de las urbes de todo el mundo. El escritor o la escritora tienen abiertas las interrogantes acerca de la emergencia de esos sujetos que buscan una vida propia y una voz como las mujeres, los homosexuales, los inmigrantes, los jóvenes, y también pueden acercarse a los infinitos matices de la vida urbana, multicultural, tecnointermediada que nos ha tocado en suerte. Una literatura tan interesada por la historia, por la problemática de la subjetividad y por la vivencia urbana como la latinoamericana, responde a la necesidad de entender nuestra vida en el mundo de un modo que escapa a esa suerte de ambición de transparencia tan cara a ciertos críticos de los Estudios Culturales y que se relaciona con la “'eficacia directa' del testimonio y de los medios masivos” (Avelar 43). Y ese modo tienen que ver con que la literatura es exploración del lenguaje. Nicholas Negroponte, gran y adinerado gurú de la computación, dice sin ambages y sin los miedos y vergüenzas que tenemos los letrados con nuestra actividad poco exitosa y minoritaria, lo que significa la palabra en el mundo actual en relación con el libro:

Yo sostengo que un libro digital nunca se agota y que no es necesario pagar el papel y el transporte desde la planta editorial hasta la librería, a la vez que se elimina el costo de mantenerlo en stock. Esto no quiere decir que las palabras no conserven su inmensa validez: promueven la fantasía del lector mucho más que un video, donde ya todo está a la vista. Ellas obligan a imaginarse cosas [...]. (92) 
f) La imaginación, sin duda, es importante. Escamotear la proyección de cualquier actividad imaginativa es una estrategia rebatible desde el punto de vista analítico, educativo, crítico y político. La imaginación, entre otras cosas, lleva a las minorías a rebelarse frente a las exclusiones de las que son víctimas, a combatir las consecuencias de nuestros fracasos políticos y sociales, a entender las sociedades cambiantes y contradictorias en que vivimos. Aquiles Esté (155), experto en semiótica, afirma que la ciencia ficción será considerada la filosofía del siglo xx porque ha sido capaz de pensar en las hipótesis que abre la tecnología para el comportamiento humano. José Joaquín Brunner (30), sociólogo, afirma que la literatura permite conocer la vida cotidiana de la gente de un modo que las metodologías sociológicas no permiten. Y es que si de algo pueden estar seguros los escritores, es que primero será un crítico literario convertido a sociólogo de la cultura el que cuestione la literatura, que un verdadero sociólogo, un semiólogo, un historiador o un científico. A éstos todavía el lenguaje los asombra, a algunos críticos no. $\mathrm{Y}$ en esto, algunos ex estudiosos de literatura se hermanan con el mercado: lo fácil vende, lo difícil carece de éxito. El escritor y la escritora cuenta con el lenguaje como el mayor promotor de la imaginación, lo cual es una perfecta razón para hacer literatura. Además, sólo los más imaginativos podrán hacer frente a ese "shock del futuro” que estamos viviendo. Dejar la ciencia, la literatura, el arte, la imaginación en manos de las elites, será confirmar su situación de dominio en el mundo: los herederos de la izquierda contemporánea sorpresivamente refuerzan el poder que dicen querer cuestionar (Chomsky citado por Sokal 222). ${ }^{11}$

g) Aunque hasta ahora he planteado críticamente el problema del mercado, está muy lejos de mis intenciones un rechazo a lo que significa. Creo que el escribir en este momento implica reconocer su dinámica e insertarse en aquellos nichos de él que convengan a determinados proyectos literarios. Todavía hay mercado para la literatura porque, entre otras cosas, varios segmentos de público se interesan en ella. Hay que aprovecharlos porque el problema del gran público con la literatura no es político, ideológico o epistemológico: tiene que ver con que es más difícil leer un libro que hacer otras cosas. Hay que ver entonces al mercado (tanto el tradicional como el que está abriendo Internet) más que como un enemigo como un posible aliado siempre visto con cuidado y mesura.

h) Los escritores en este momento se encuentran ante una extraña paradoja: su actividad contradice abiertamente la racionalidad laboral burguesa, pero al mismo tiempo requiere de dominio del oficio, de muchas horas y trabajo. Y esta condición choca con la idea actual del arte y el artista, ligados directamente al espectáculo, y cuyas habilidades personales en cuanto a dominio de una especialidad son irrelevantes. Lo que interesa de Ricky Martín y de Shakira es su espectacularidad y belleza, no sus dotes musicales. No se trata de una crítica a estos cantantes (personalmente me agradan). Lo que trato de decir es que la idea de genialidad, tan mal vista actualmente y con cierta razón, de talento y de aptitudes se han desplazado a otros campos. Los científicos, los hackers que hacen temblar al universo virtual, los tecnólogos, los futbolistas estrella, los agentes de bolsa, los

${ }^{11}$ Por fortuna, los subalternos que quieren cambiar su situación saben esto muy bien: Rigoberta Menchú y el Subcomandante Marcos no le tienen asco a nada que les pueda servir para sus fines venga de quien venga. 
narradores orales, los bailarines populares o elitescos no tienen problemas en aceptar que el virtuosismo es parte de su profesión. Y virtuosismo en literatura es dominio del lenguaje, lo cual no pareciera interesar especialmente al mercado masivo, a la sociología de la literatura y a algunos críticos. El escritor debe entonces entender que empeñarse en el trabajo literario no le dará las recompensas de otras épocas, en términos de prestigio social.

i) Ni escritores ni críticos deben exagerar las consecuencias de la tecnología: la tecnología da la posibilidad de explorar y llevar al límite opciones que ya la literatura ha hecho suyas: la ruptura del relato aristotélico, a la que alude Landow, fue hecha por la literatura contemporánea mucho antes de la aparición del hipertexto. Además, la poesía de ambos lados del Atlántico pulverizó la linealidad de la prosa y la idea de la coherencia expositiva cuando las computadoras eran si acaso ciencia ficción. La libertad extrema del navegante en Internet, que es vista como la necesaria dinamita que hará saltar todas las consideraciones actuales sobre la enseñanza, el aprendizaje, el manejo de la información y la autoría, tiene un inconveniente práctico: el que no sepa por qué navega, hacia dónde y qué quiere buscar, perderá el tiempo o usará Internet para pasar el rato o para aburrirse. Los estudiantes, profesores, lectores de literatura se verán obligados a tener una formación rigurosa si no desean perderse en una inmensa maraña de datos sin clasificación. La libertad de escoger es una quimera si no se tienen criterios mínimos para la escogencia: me da igual un texto en congolés que uno en sueco porque no conozco ninguna de las dos lenguas.

h) Cualquier joven aficionado a los juegos de video sabe que su participación y brillantez dependen también de las opciones que el juego ofrezca. Llama la atención que el ansioso espíritu igualitario de George Landow respecto a la relación autor-lector olvide una premisa simple de cualquier actividad deportiva: todos podemos jugar fútbol, pero no todos somos Maradona. El creador de la Legenda de Zelda, un juego de video muy popular, tuvo la buena estrella de entender tanto la dinámica tecnológica de su potencial público como el atractivo de los relatos de aventura, la novela de formación y las imágenes propias de la estética gótica: el jugador sigue las líneas maestras de quien hizo el juego. Y no todos pueden tener la competencia tecnológica y cultural que amerita hacer esas líneas maestras. La literatura, sin duda, tendrá que vérselas con las nuevas tecnologías pero desde otra perspectiva. En primer lugar, el lector de hoy día es un lector "hipertextual”, que está asediado por un sin fin de imágenes, textos, sonidos y estímulos de todo tipo. Ese lector quizás ya no sea tan concienzudo como los de otras épocas. En segundo lugar, Internet o el libro electrónico no parecen precisamente ideales para difundir gruesas novelas, pero favorecen la poesía y el cuento y dan pie a escrituras que combinan la imagen y el sonido y que pueden convertir la lectura silenciosa de signos en papel en una aventura disruptiva y saltimbanqui entre texto, imágenes y sonidos. Por ahora, todavía queda mucho camino por andar, pero el autor de literatura seguirá existiendo por un buen tiempo más. Si la autoría forma parte de la "ideología humanista de lo literario" que favorece abiertamente el individualismo y el espíritu anticomunitario (Beverley 35), pues qué remedio: no formamos parte de sociedades tradicionales con fuertes lazos comunitarios (basados en unas cuantas ocasiones en recias tradiciones patriarcales, en un rechazo frontal a toda forma de disidencia y en la condena a formas distintas de ver el mundo, es decir, en cosas 
que yo rechazo de mi propia cultura porque me inclino por otras opciones). Formamos parte de sociedades contradictorias, terribles y cambiantes donde el individuo puede seguir constituyéndose en una opción de resistencia, a pesar de que sabemos sus limitaciones y de que la idea de una subjetividad todopoderosa ha sido cuestionada por el posestructuralismo.

BiBLIOGRAFÍA

Avelar, Idelber. "Bares desiertos y calles sin nombre: literatura y experiencia en tiempos sombríos”. Revista de Crítica Cultural 7 (1993): 37-43.

Alarcón, Norma. “La frontera de Andalzúa. La inscripción de una ginocrítica”. Cultura y Tercer Mundo. Nuevas identidades y ciudadanías. Beatriz González, ed. Vol.2. Caracas: Nueva Sociedad, 1996. 121-146.

Beverley, John. “¿Hay vida más allá de la literatura?” Estudios 6 (1995): 23-40.

Bourdieu, Pierre. Las reglas del arte. Génesis y estructura del campo literario. Barcelona: Anagrama, 1995.

Brunner, José Joaquín. “Sobre el crepúsculo de la sociología y el comienzo de otras narrativas”. Revista de Crítica Cultural 15 (1997): 28-31.

Chartier, Roger. Cultura escrita, literatura e historia. Conversaciones con Roger Chartier. México: Fondo de Cultura Económica, 1999.

Este, Aquiles. Cultura replicante. El orden semiocentrista. Barcelona: Gedisa, 1997.

Franco, Jean. "Literatura y crítica literaria en la época del neoliberalismo”. Medio siglo de literatura latinoamericana (Memorias del Primer Congreso Internacional). Ed. Ana María Domenella, Antonio Marquet y otros. Vol. 1. México: Universidad Autónoma Metropolitana, 1997. 217-30.

Iser, Wolfgang. “La ficcionalización: dimensión antropológica de las ficciones literarias”. Teorías de la ficción literaria. Madrid: Arco/Libros, 1997. 43-65.

Landow, George. Hipertexto. La convergencia de la teoría crítica contemporánea y la tecnología. Barcelona: Paidós, 1992.

Martín Barbero, Jesús. De los medios a las mediaciones. Bogotá: Convenio Andrés Bello, 1998.

“Nuevos modos de leer”. Revista de Crítica Cultural 7 (1993): 19-26.

Negroponte, Nicholas. Entrevista: “Las computadoras podrán ver y oír”. Daniel Ulanovsky Sack. Los desafíos del nuevo milenio. Buenos Aires: Aguilar, 1999.

Olaechea, Juan. El libro en el ecosistema de la comunicación cultural. Madrid: Biblioteca del Libro, 1986.

Richard, Nelly. “Feminismo, experiencia y representación”. Revista Iberoamericana 176177 (1986): 733-44.

"Intersectando Latinoamérica con el latinoamericanismo: saberes académicos, práctica teórica y crítica cultural”. Revista Iberoamericana 180 (1997): 345-61.

Rojo, Grínor. "Crítica del canon, estudios culturales, estudios postcoloniales y estudios latinoamericanos: una convivencia difícil”. Mapocho 43 (1998): 73-84.

Salabert, Pere. “Arte, tiempo, identidad”. Fin de un siglo: las fronteras de la cultura. Rosario: Homo Sapiens Ediciones, 1996. 15-45. 
Sarlo, Beatriz. "Los Estudios Culturales y la Crítica Literaria en la encrucijada valorativa”. Revista de Crítica Cultural 15 (1997): 32-37.

Sokal, Alan y Jack Bricmont. Imposturas intelectuales. Barcelona: Paidós, 1999.

Torres, Ana Teresa. "El escritor ante el siglo XXI". A beneficio de inventario. Caracas: Memorias de Altagracia, 2000. 67-75.

"Balza y las mujeres”. A beneficio de inventario. Caracas: Memorias de Altagracia, 2000. 49-50.

"De novela, mercado y exotismo". A beneficio de inventario. Caracas: Memorias de Altagracia, 2000. 17-21.

Ulanovsky Sack, Daniel. Entrevista a Nicholas Negroponte. "Las computadoras podrán ver y oír”. Los desafíos del nuevo milenio. Buenos Aires: Aguilar, 1999.

Williams, Raymond. Marxismo y literatura. Barcelona: Península, 1980.

${ }^{12}$ Por fortuna los subalternos que quieren cambiar su situación saben esto muy bien: Rigoberta Menchú y el Subcomandante Marcos no le tienen asco a nada que les pueda servir para sus fines venga de quien venga. 